\title{
Correction to: Current therapies in alleviating liver disorders and cancers with a special focus on the potential of vitamin D
}

Shahida Khan ${ }^{1 *}$, Ashraf Ali ${ }^{1}$, Sarah Khan ${ }^{2}$, Ahmed Bakillah ${ }^{3}$, Ghazi Damanhouri ${ }^{1}$, Aziz Khan ${ }^{1}$, Ahmad Makki ${ }^{1}$, Ibtehal AlAnsari ${ }^{1}$ and Naheed Banu ${ }^{4}$

\section{Correction}

Following publication of the original article [1] one of the authors wrote to say that his name had been spelt incorrectly as Ahmed Makki instead of Ahmad Makki.

The original article has been corrected.

\begin{abstract}
Author details
${ }^{1}$ Applied Nutrition and Natural Products Group, King Fahd Medical Research Center, King Abdulaziz University, P.O.Box 80216, Jeddah 21589, Kingdom of Saudi Arabia. ${ }^{2}$ National Brain Research Center, Manesar, Gurgaon 122051, India. ${ }^{3}$ Department of Medicine, SUNY Downstate Medical Center, 450 Clarkson Avenue, Brooklyn, NY 11203, USA. ${ }^{4}$ Department of Biochemistry, College of Medical Rehabilitation, Buraydah, Qassim University, P.O. Box 51452, Qassim, Kingdom of Saudi Arabia.
\end{abstract}

Received: 13 March 2018 Accepted: 13 March 2018

Published online: 16 March 2018

\section{Reference}

1. Khan S, Ali A, Khan S, Bakillah A, Damanhouri G, Khan A, Makki A, AlAnsari I, Banu N. Current therapies in alleviating liver disorders and cancers with a special focus on the potential of vitamin D. Nutr Metab. 2018;15:13. https:// doi.org/10.1186/s12986-018-0251-5.

\footnotetext{
* Correspondence: sakhan01@kau.edu.sa; shahidakhan2009@gmail.com

${ }^{1}$ Applied Nutrition and Natural Products Group, King Fahd Medical Research Center, King Abdulaziz University, P.O.Box 80216, Jeddah 21589, Kingdom of Saudi Arabia

Full list of author information is available at the end of the article
} 